\title{
ORIGINAL ARTICLE Comparative international analysis of radiofrequency exposure surveys of mobile communication radio base stations
}

\author{
Jack T. Rowley ${ }^{1}$ and Ken H. Joyner ${ }^{2}$
}

This paper presents analyses of data from surveys of radio base stations in 23 countries across five continents from the year 2000 onward and includes over 173,000 individual data points. The research compared the results of the national surveys, investigated chronological trends and compared exposures by technology. The key findings from this data are that irrespective of country, the year and cellular technology, exposures to radio signals at ground level were only a small fraction of the relevant human exposure standards. Importantly, there has been no significant increase in exposure levels since the widespread introduction of $3 \mathrm{G}$ mobile services, which should be reassuring for policy makers and negate the need for post-installation measurements at ground level for compliance purposes. There may be areas close to antennas where compliance levels could be exceeded. Future potential work includes extending the study to additional countries, development of cumulative exposure distributions and investigating the possibility of linking exposure measurements to population statistics to assess the distribution of exposure levels relative to population percentiles.

Journal of Exposure Science and Environmental Epidemiology (2012) 22, 304-315; doi:10.1038/jes.2012.13; published online 29 February 2012

Keywords: EMF; environmental monitoring; personal exposure

\section{INTRODUCTION}

It is estimated that over $90 \%$ of the global population has access to mobile networks and that there were 5.3 billion mobile subscriptions at the end of $2010 .^{1}$ Services are provided by a network of radio base stations and it was estimated that there were over 1.4 million installed globally in 2006 (ref. 2) with a 2008 industry analyst report projecting 4.7 million base stations at the end of 2010, with annual growth of about $200,000 .^{3}$ In addition to growth in subscribers, there has also been a rapid evolution in mobile radio technology. ${ }^{4}$ Risk perception studies show that some communities, members of the general public, academics and politicians have concerns about possible health effects of exposure to radiofrequency (RF) energy transmitted by mobile phones and wireless networks. ${ }^{5}$

In an effort to provide public information and allay community concerns, regulatory agencies and academic institutions have undertaken extensive measurement surveys of the environmental levels of RF energy in locations near the individual transmitter sites of mobile networks and made the results publicly available. The World Health Organization (WHO) also recommends on-going work to characterize population RF exposure and notes that this would be particularly useful for global exposure assessment in view of the upcoming WHO health risk assessment for RF fields. ${ }^{6}$ There have been limited efforts to compile and compare survey data between countries ${ }^{7-9}$ and each found that RF exposures in publicly accessible areas were typically many thousands of times below the levels recommended in international human exposure guidelines. $^{10} \mathrm{~A}$ recent cumulative distribution analysis of UK measurements (a subset of the same data used in our study) reported a median exposure level of $0.0037 \mu \mathrm{W} / \mathrm{cm}^{2}$ with 5 th and 95th percentiles of $1.3 \times 10^{-5} \mu \mathrm{W} / \mathrm{cm}^{2}$ and $0.11 \mu \mathrm{W} / \mathrm{cm}^{2}$, respectively. ${ }^{11}$
The aims of our research project were to build on the earlier analysis and:

(1) Compile a summary of key characteristics of national measurement surveys of public RF exposures from radio base stations in a large sample of countries.

(2) Investigate similarities or differences between the results of various national RF surveys and different technologies or frequency bands (where sufficient information was available).

(3) Investigate any chronological trends in the exposure data where individual national surveys may have been conducted over a number of years.

\section{METHODS}

Two primary criteria were applied to the selection of RF measurement surveys for inclusion in this study:

(1) The data had to be accessible, either from published sources (journal or website) or freely supplied on request from the owners of the data. The vast majority of data (over 99.6\%) has been sourced from government agencies, universities or independent research institutes.

(2) The survey instrumentation used for the measurements was capable of frequency/service differentiation and the data reported per mobile technology and service band of interest or, at a minimum, the total level across all the mobile phone bands present.

Where possible we asked for the raw measurement data and if this was not available then we asked for summary information (minimum, maximum, mean, standard deviation, number of points and measurement years). It was also important that the data were available as field strength levels rather than as percentage of relevant human exposure standard as

${ }^{1}$ GSM Association, Public Policy, 7th Floor, 5 New Street Square, London EC4A 3BF, UK; ${ }^{2}$ Joyner and Associates (Telecommunications Industry Consultants), 34 Barrow Drive, Heathmont, Victoria 3135, Australia. Correspondence to: Dr. Jack T. Rowley, GSM Association, Public Policy, 7th Floor, 5 New Street Square, London, EC4A 3BF, UK.

Tel.: + 35386806 0849. Fax: + 35316865023.

E-mail: jrowley@gsm.org

Received 6 April 2011; accepted 16 November 2011; published online 29 February 2012 
the specific service frequency was not always available for conversion purposes. We obtained data on the extensive Italian national measurement program, $^{12}$ but we do not yet have access to the software needed to analyze nearly 50 million measurement samples and intend to include the results in a future publication. Table 1 summarizes the sources of the surveys for 23 countries, their main characteristics and expands the abbreviated names of the mobile technologies. The US data set was unique in that a majority of the measurements were made on rooftops and buildings within close proximity of the transmitting antennas. All other data sets were primarily ground-based measurements around towers or elevated installations.

There are four general methods of assessing exposure levels to RF fields. These methods include narrowband and broadband measurements, ${ }^{57}$ personal RF dosimeters and theoretical calculations. In this study, we have

Personal RF dosimeters have been used to assess personal exposure in population samples, ${ }^{58}$ however, we did not use data from these measurements because they have limited sensitivity, are affected by coupling with the body of the wearer and assess individual exposure rather than exposure at a location. ${ }^{59,60}$ Theoretical calculations have also not been used as they generally over-estimate actual levels because of the use of worst case assumptions.

In brief, broadband instruments, which have frequency responses typically several hundred kilohertz up to several gigahertz, can be used to measure the total RF power across the frequency bands covering FM radio/ TV broadcast and radio base stations, but frequency- or channel-specific

Table 1. Countries from which data were sourced, the years over which the surveys were carried out, the number of data points, the measurement method and the types of services measured.

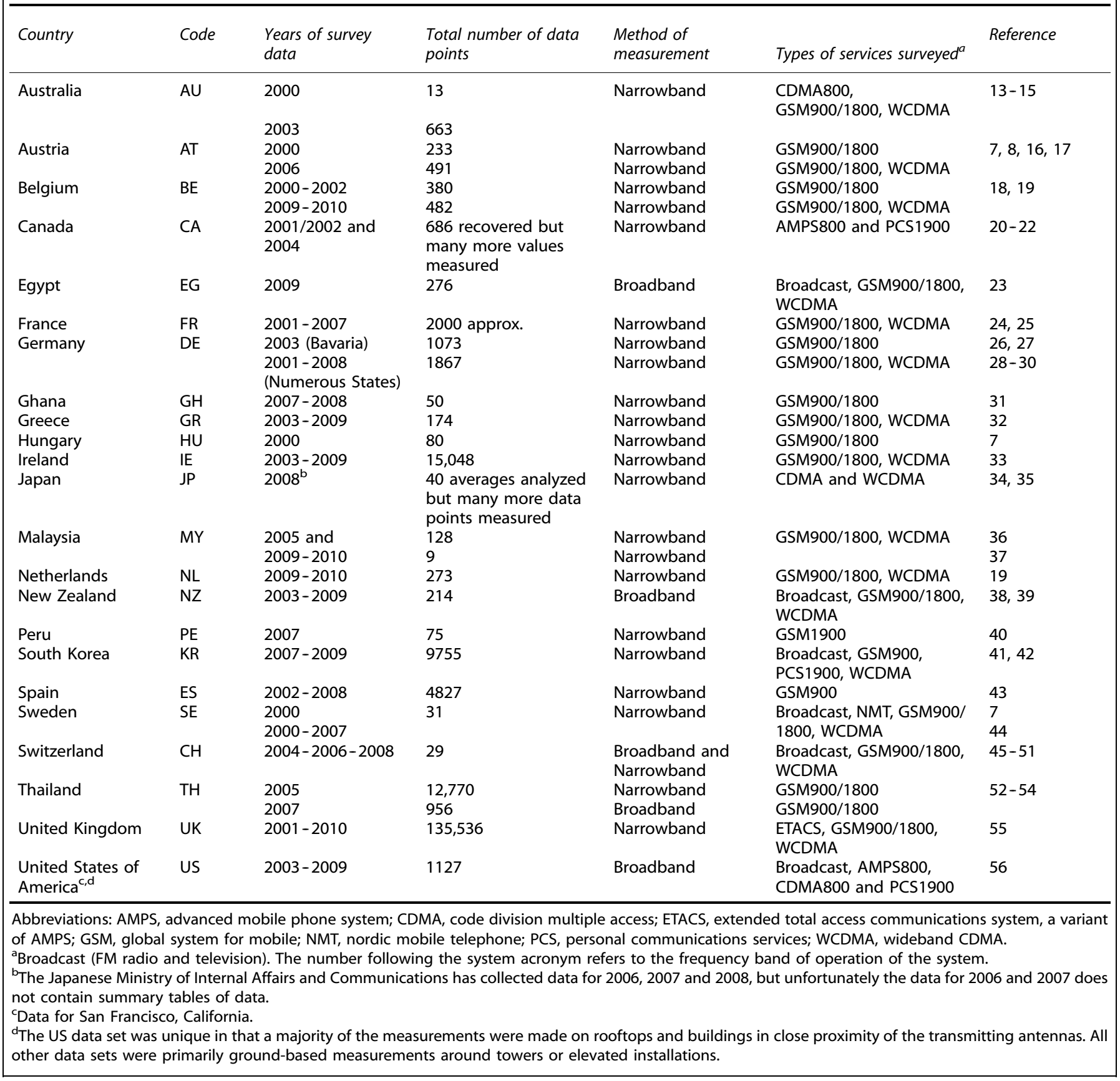


information is often not available or not easily obtained. As a general comment for comparisons purposes such as presented here, broadband measuring instruments have limitations because of their lack of frequency selectivity and also because they are designed to indicate higher levels relative to the various exposure limits and are used closer to RF sources than other measuring techniques such as narrowband instruments. Often, however, the contribution from a specific source can be assessed because a dominant source can be identified through proximity or by switching sources on and off to measure their contribution to the total RF background. Broadband instruments have a sensitivity threshold to electric fields above the equivalent of $0.01 \mu \mathrm{W} / \mathrm{cm}^{2}{ }^{261}$

Narrowband or frequency-specific instruments have higher sensitivity and are able to discriminate between the various RF sources. However, it can also be difficult to directly compare narrowband measurements from different surveys as the operational parameters of the spectrum analyzers or frequency selective receivers may be different. For example, differing resolution bandwidths and peak hold or time averaged modes can be selected. The survey techniques can also be different, e.g., is an area scanned and only the peak field reported or are the levels spatially averaged in some manner, are single polarizations or isotropic responses reported? The total RF field from narrowband surveys is found by summing the power density of the exposure across the frequency band of interest. Narrowband instruments can typically detect electric fields 4-5 orders of magnitude below broadband instruments but this is very dependent on the amount of amplification and the signal processing involved in the setup.

There have been significant advances in both broadband and narrowband instrumentation over recent years, which have addressed the issues of size, portability and isotropic response of the instrumentation and the choice between the two types of instrumentation is now one of cost and purpose. For the purpose of demonstrating compliance of a particular installation, broadband measurements may be sufficient However, measuring particular sources or their contribution to the total background generally requires some means of identifying the various frequencies present and is particularly true of complex sites with multiple transmitters and services, and in urban areas.

\section{RESULTS}

In Table 2, the data have been pooled by country, year (where the annual data are available) and by wireless technology (generally only for narrowband measurement surveys). We excluded Ghana and France from the analysis due to incomplete survey information, so analysis was based on 21 countries. The statistical values calculated for each data set are minimum, maximum, mean and standard deviation. Note that data are presented as absolute power density levels in the units of $\mu \mathrm{W} / \mathrm{cm}^{2}$-the levels are not relative to the respective human exposure limits for RF fields, which vary by frequency. ${ }^{10}$ A total of 175,547 data points were collected in this study but due to incomplete information and problems of interpretation only 173,323 points (98.7\%) were included in the analysis.

Figure 1 compares the survey results across the 21 countries. We calculated a global average across all measurements, weighted by the number of points per country, as $0.0567 \mu \mathrm{W} / \mathrm{cm}^{2}$ as indicated by the lower dotted line in Figure 1. The weighted average was calculated as shown in Eq. (1):

$$
\text { global weighted average }=\frac{\text { country weighted average } \times \text { number of points }}{\text { global number of points }}
$$

Where the country-weighted average was based on the number of measurements for each radio technology relative to the total number of measurements. There was approximately three orders of magnitude difference between the mean values for the country data sets. Two key factors may explain the difference in mean levels. First, the use of broadband versus narrowband instrumentsnot surprisingly the broadband measurements yield the highest average values and the narrowband measurements the lowest average values. Second, the choice of measurement location was not standardized between countries (most were at ground level except the USA which included a large number of rooftops) Measurements in Germany near 11 different GSM (Global System for Mobile Communications-typically refers to $2 \mathrm{G}$ or second generation systems) and $3 G$ (third generation) base station types (urban, rural, indoor, outdoor, etc) found that the exposure varied by three orders of magnitude due to choice of measurement location. $^{62}$

In Figure 2, the results of the annual surveys for the UK and the USA are plotted with the annual averages for Spain, Greece and Ireland. These countries were selected because of the number of years surveyed and also to allow a comparison of trends between narrowband (UK, ES, GR, IE) and broadband (US) measurements. The very limited variation year on year between surveys in the same country is striking in Figure 2. During the period of the UK measurements subscribers grew from 42.9 million to 77.5 million (81\%) and for the US from 50.9 million to 283.1 million (456\%) ${ }^{63}$ and $3 \mathrm{G}$ technologies were deployed but average exposure measured in the surveys remained largely unchanged. This is probably indicative of the within-country similarities with respect to survey methodology, survey equipment, mobile network structure and the choice of measurement location. The UK averages are 2-3 orders of magnitude lower than those for Spain, Greece and Ireland and we believe this is due to very low reported sensitivity of the UK measurements and differences in proximity to the antennas. The US measurements included many rooftops and other locations around the immediate vicinity of base station antennas. Measurements on rooftops close to the antennas would reveal readings that could be significantly higher, and exceed reference levels for the public directly in front of transmitting antennas. ${ }^{64}$ The general survey approach in the US is to spatially average the RF fields over the height of a person, typically taken as $1.8 \mathrm{~m}$. Also in the US, measurements are generally made to identify the contour of the maximum exposure level for the public as it may also apply to workers on the rooftop who have not been trained and not aware of their exposure. Finally, we note that while the mobile technologies are deployed nationally throughout the US, the measurements are for one city only.

Figure 3 compares exposure by technology averaged for 16 countries and all available years from data measured using narrowband survey techniques. It is clear from this graph that, apart from the Mobile $800 \mathrm{MHz}$ band (limited measurements in Canada and the UK only) and the GSM1900 (early deployment in Canada in 2003) and excluding current LTE (Long Term Evolution or 4G-4th generation system) with very limited deployment, all of the technology averages are within about a factor of 10 of $0.1 \mu \mathrm{W} / \mathrm{cm}^{2}$.

\section{DISCUSSION}

This large-scale international comparative analysis of the results of RF exposure surveys of mobile communications networks has a number of limitations. Caution must be observed in comparing absolute values between countries because of differing measurement instruments (e.g., narrowband spectrum analyzers or broadband survey instruments) and the criteria for selecting the measurement locations was not standardized between countries. In addition, our study does not allow any conclusions in regard to the percentage of the total population exposed to RF signals from base stations though it seems likely that this will have increased over time as networks were expanded to meet coverage obligations in license conditions. However, a number of observations in respect of the types of base stations surveyed and the 


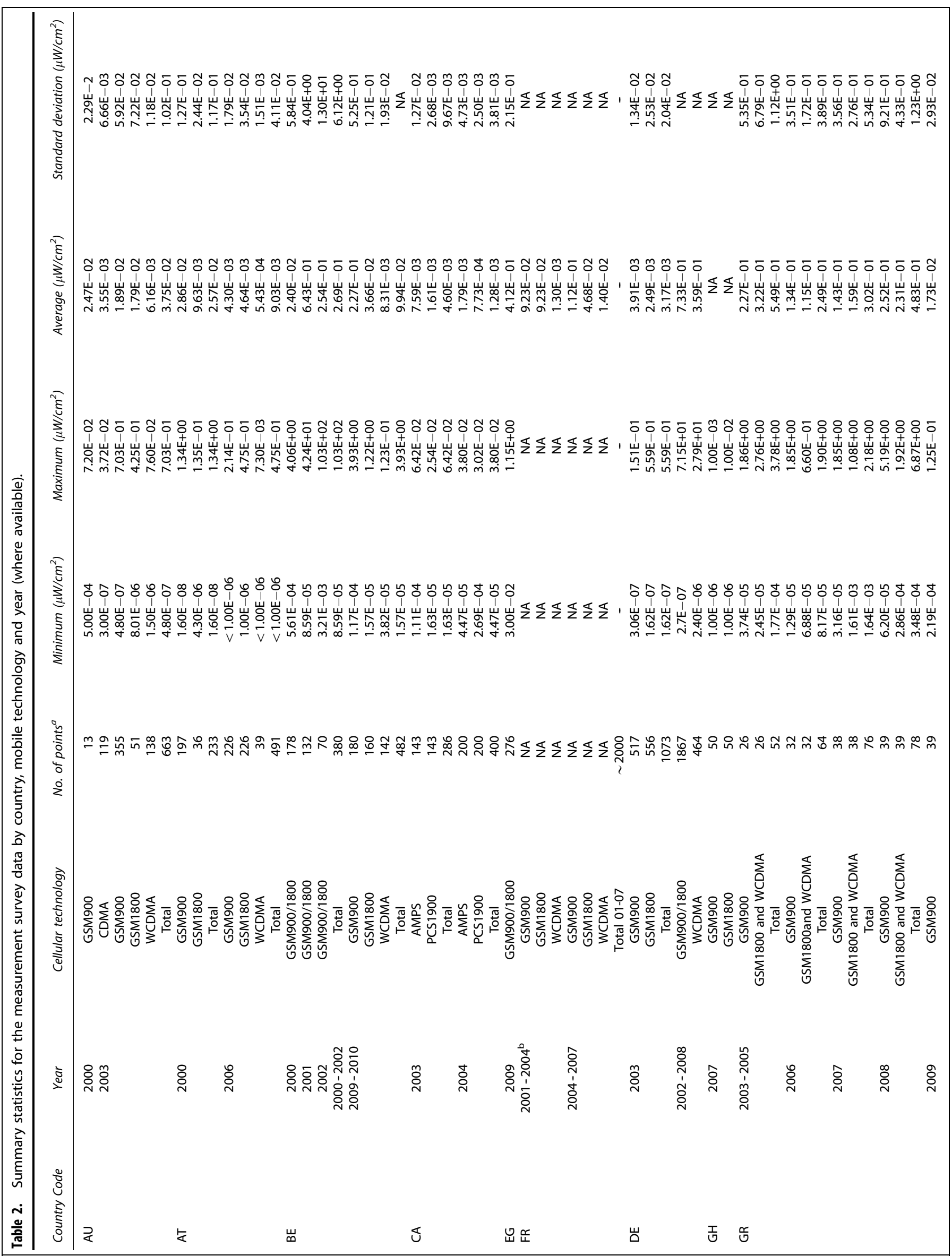




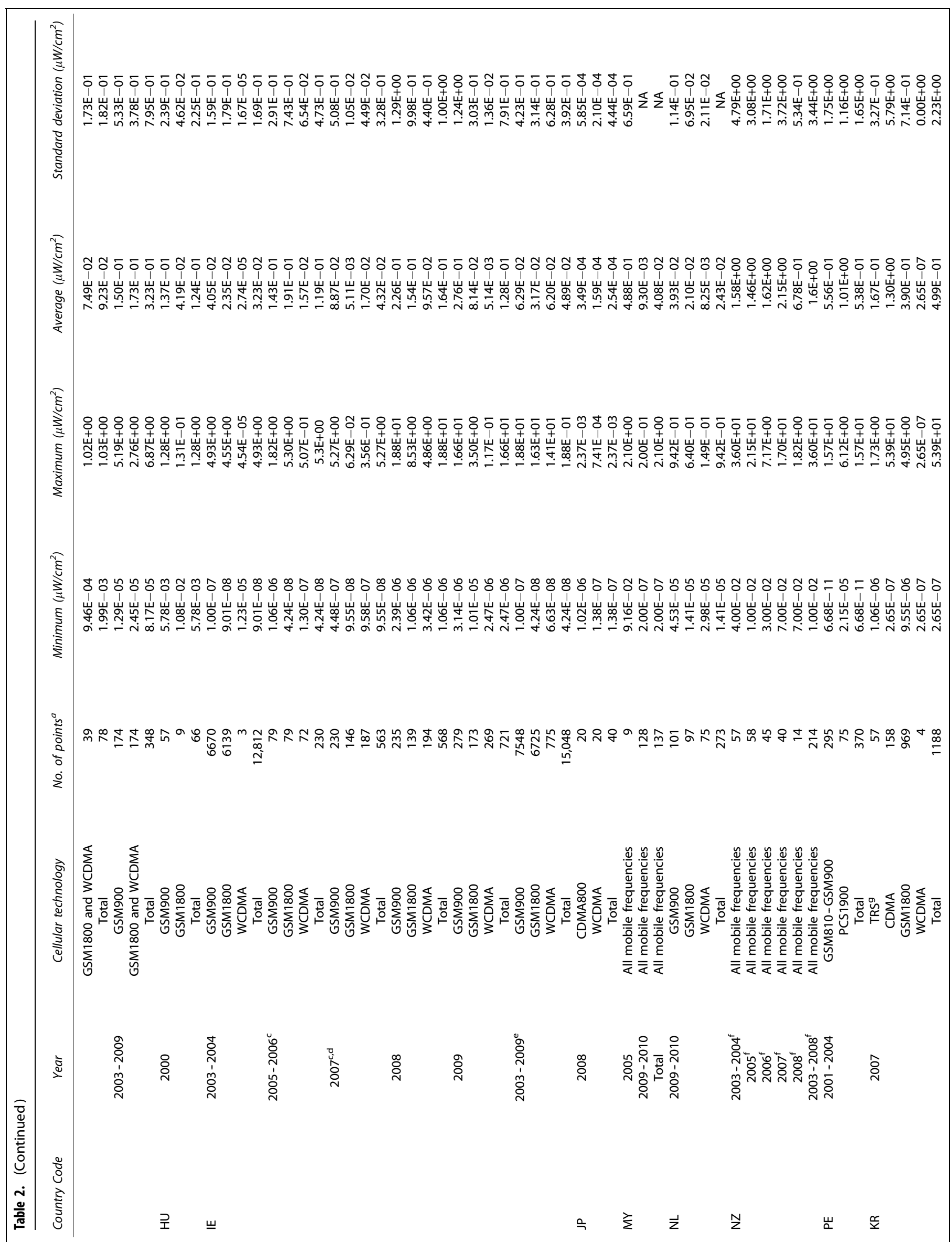




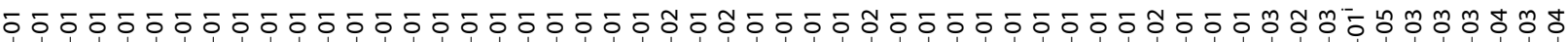

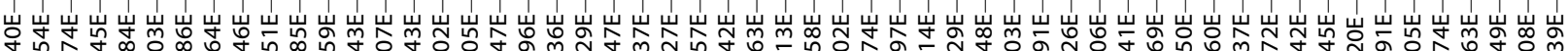

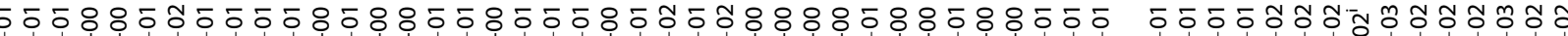

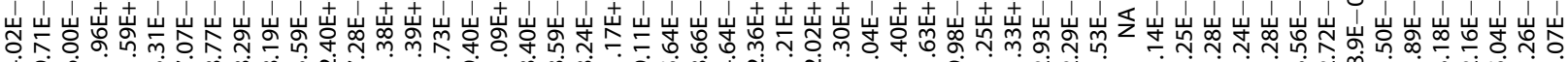
m r

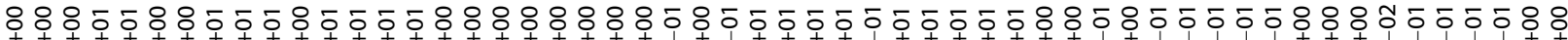

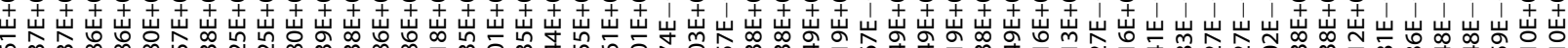
ơ

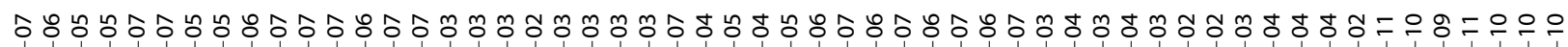

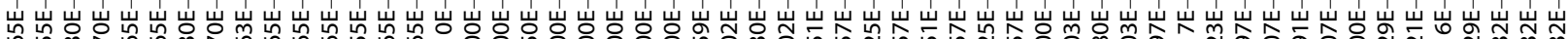
i

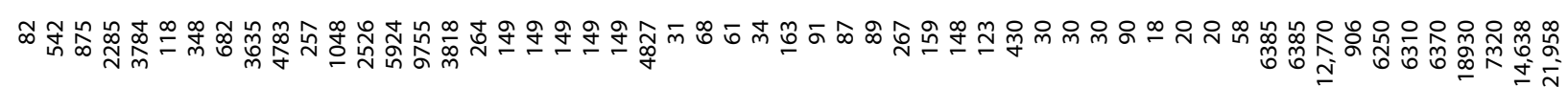




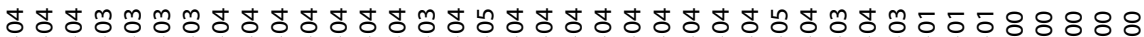

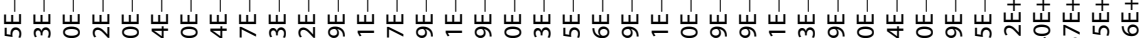

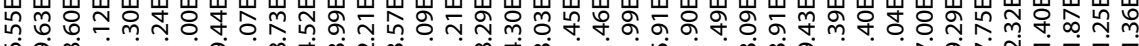

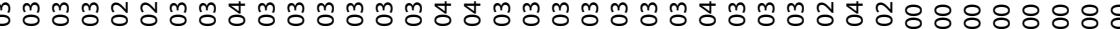

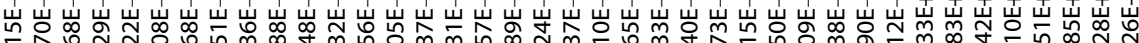
ঢ́

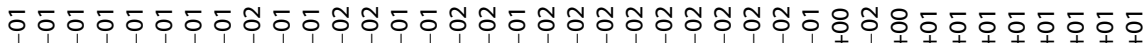

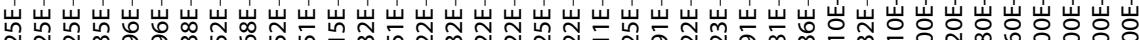

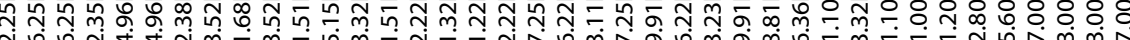
$\sum^{\frac{1}{a}}$

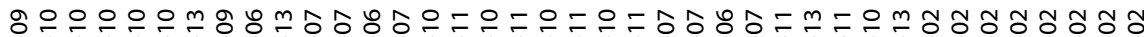

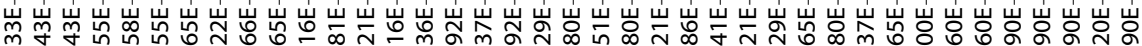
- $\wedge$ in

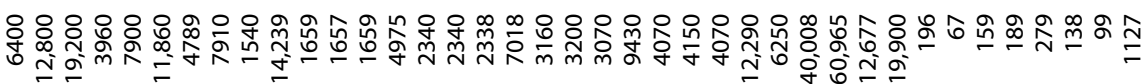
$\dot{2}$

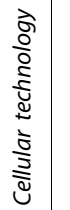

৪ ৪্০

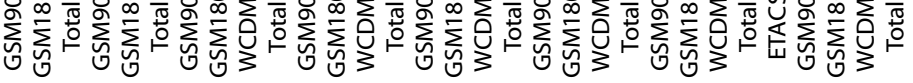

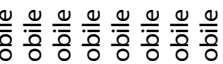

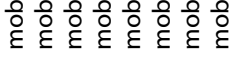

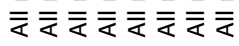

ร

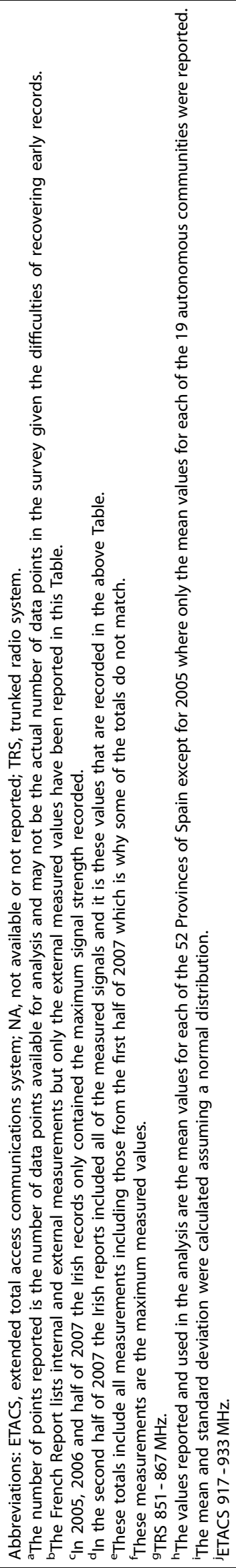




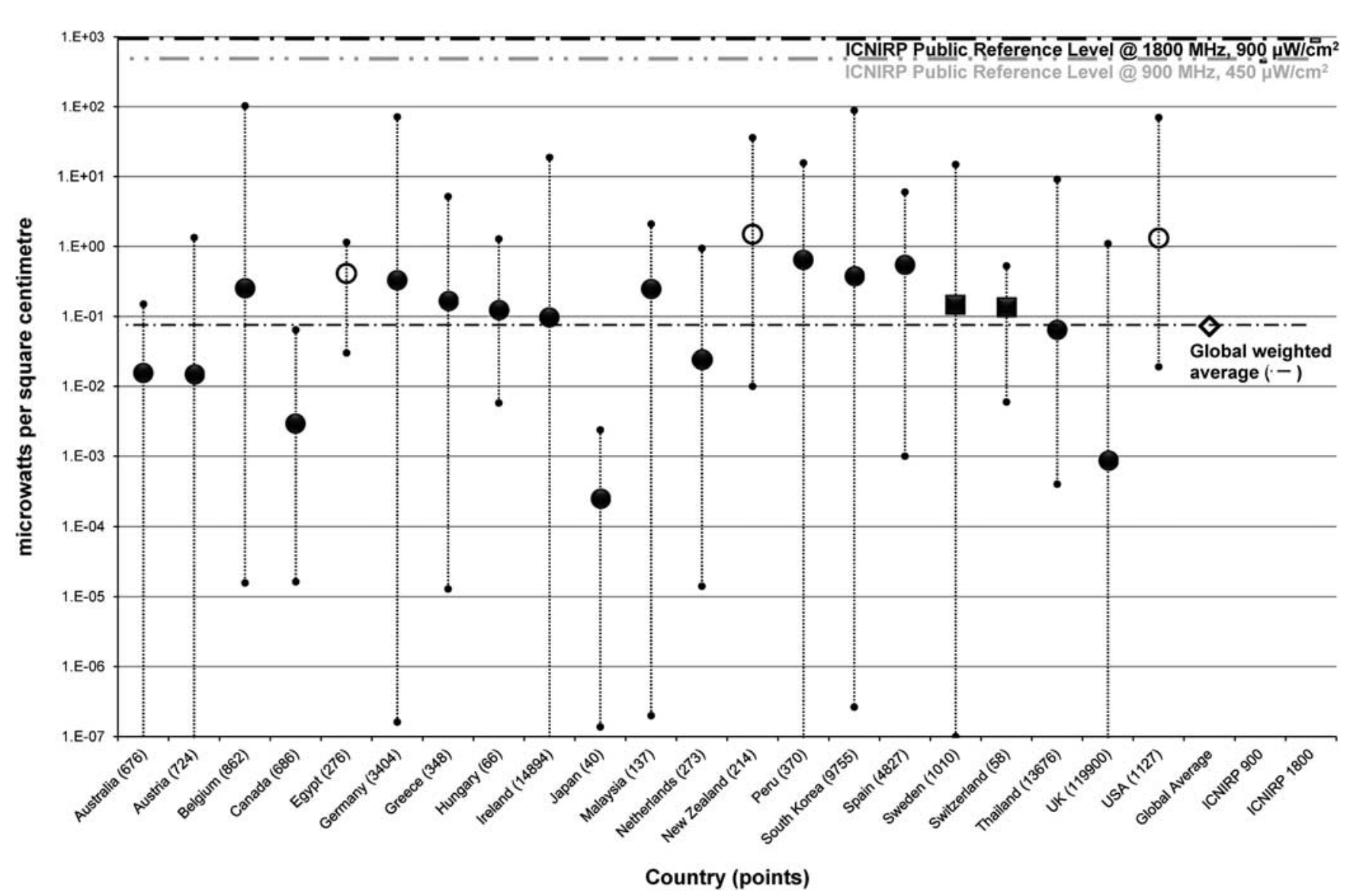

Figure 1. Minimum $(\bullet)$, maximum $(\bullet)$ and narrowband average $(\bullet)$, broadband average $(\bigcirc)$ or mixed narrowband/broadband average $(\boldsymbol{\square})$ of all survey data for each country with the number of measurement points for the country in brackets. For comparison, the global weighted average marked with dot-dashed line through $(\diamond)$ and the ICNIRP reference levels for the public at 900 and $1800 \mathrm{MHz}$ are also plotted.

locations at which measurements were made are clear from the results.

Mobile networks comply with RF exposure limits

From an inspection of each of the figures, it can be seen clearly that, irrespective of the year the survey was performed or the country the survey was conducted in, all the survey data complied with the ICNIRP Guidelines ${ }^{10}$ and the US Federal Communication Commission Rules ${ }^{65}$ by a very large margin irrespective of the service band. The global average in Figure 1 at $0.073 \mu \mathrm{W} / \mathrm{cm}^{2}$ is more than 7000 times below the most restrictive ICNIRP reference level for the public relevant to these mobile communication services $\left(400 \mu \mathrm{W} / \mathrm{cm}^{2}\right.$ at $\left.800 \mathrm{MHz}\right)$. It can also be inferred from Figure 1 that the introduction of arbitrary low exposure limits would mean that many base stations would need to be reworked in some way to achieve compliance. In response to the adoption by the Salzburg (Austria) city council of a policy of $0.1 \mu \mathrm{W} / \mathrm{cm}^{2}$ in 2001, the Swiss communications regulator commissioned measurements of GSM services and concluded that it would be very difficult to achieve exposure values lower than $10 \mu \mathrm{W} / \mathrm{cm}^{2}$ without substantial economic consequences (Coray, Krähenbühl, Riederer, Stoll, Neubauer and Szentkuti, 2002).

Broadband measurements are higher than narrowband measurements

For reasons previously discussed, a priori it would be expected that broadband measurements would typically yield higher values than narrowband survey measurements. The narrowband mea- surements are made on a single channel usually a pilot channel, whereas the broadband measurements see all the active traffic channels, as well as other RF sources, within their measurement bandwidth. There are ways to adjust narrowband measurements of single pilot channels to account for the effects of live traffic channels or indeed fully loaded base stations. ${ }^{33}$ For GSM signals the relationship is:

$$
E_{\text {max }}=E_{\mathrm{BCCH}} \times \sqrt{N_{\text {channels }}}
$$

where $E_{\max }$ is the maximum electric field, $E_{\mathrm{BCCH}}$ is the GSM broadcast control channel, and $N$ is the number of traffic channels. If $N$ is unknown then it is taken as equal to 4, for a doubling of the E-field (4 times in power density).

For WCDMA (Wideband Code Division Multiple Access-3G) signals the relationship is:

$$
E_{\max }=E_{\mathrm{WCDMA}} \times \sqrt{\frac{P_{\max }}{P_{\mathrm{p}}-\mathrm{CPICH}}}
$$

where $E_{\max }$ is the maximum electric field, $E_{\mathrm{WCDMA}}$ is the WCDMA pilot control channel, $P_{\max }$ is the maximum possible WCDMA power and $P_{\mathrm{P}-\mathrm{CPICH}}$ is the power of the pilot channel. Typically, $P_{\mathrm{P}-\mathrm{CPICH}}$ transmits with a constant power at $10 \%$ of $P_{\max }$ this leads to a threefold increase of the E-field (10 times in power density).

Application to pilot channel measurements of the factors derived from Eqs. 2 and 3 allows extrapolation to the maximum RF exposure level and should improve the agreement between 


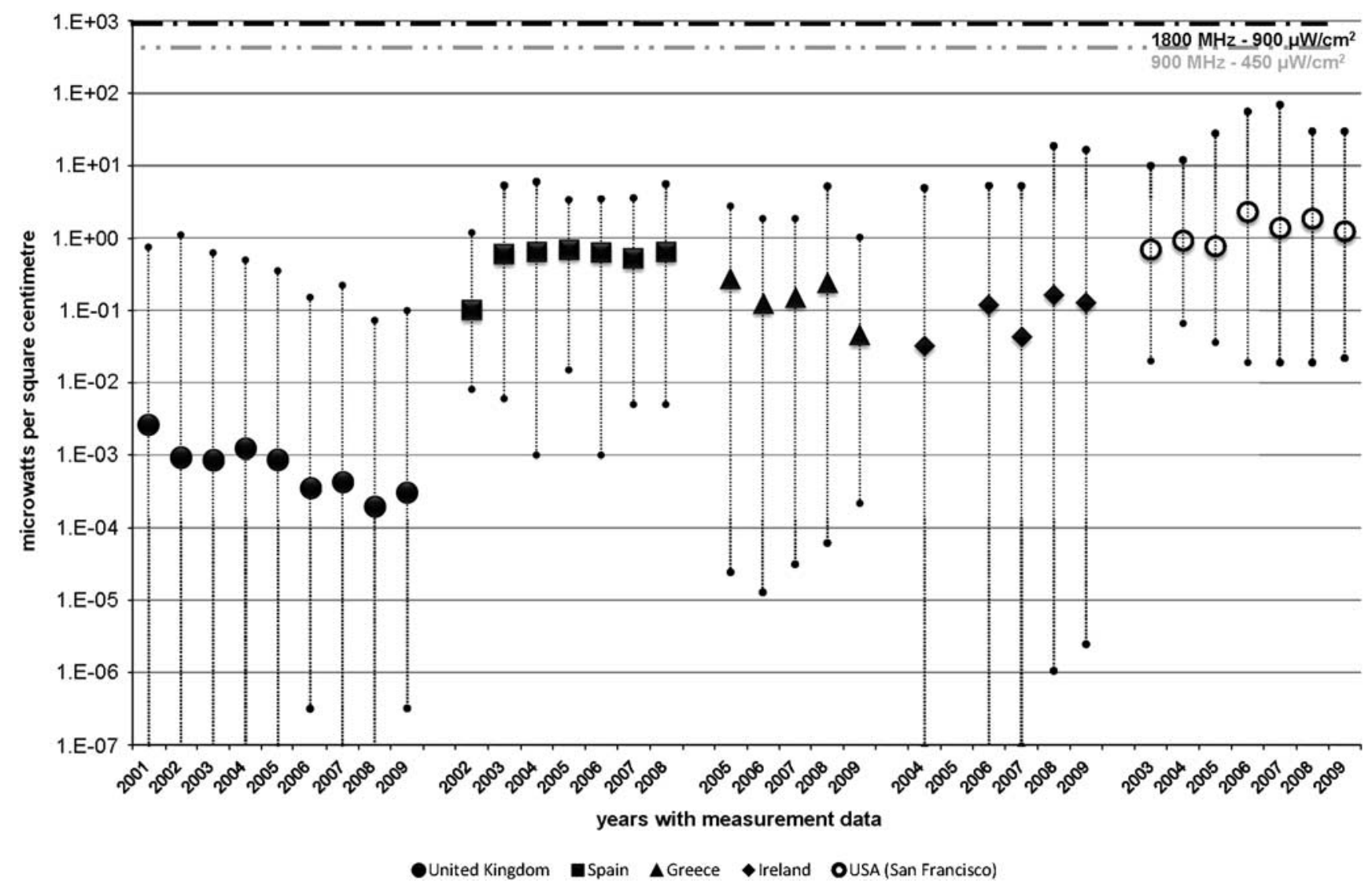

Figure 2. Minimum $(\bullet)$, maximum $(\bullet)$ and average of the narrowband measurements for the UK $(\bullet)$, Spain $(\boldsymbol{\square})$, Greece $(\boldsymbol{\Delta})$ and Ireland $(\bullet)$; and the broadband measurements for the US $(O)$, with the year of measurement data on the horizontal axis. Note that not all years were available in all countries. For comparison, the ICNIRP reference level for the public at $900 \mathrm{MHz}$ and $1800 \mathrm{MHz}$ are included.

narrowband and broadband measurements, provided no other significant RF signals are present. These extrapolation factors explain some of the variation between the narrowband and broadband measurements in Figure 1, but not the large differences for the UK in Figure 2, which we believe are more due to differences in the proximity of the measurement point to the base station and instrumentation with a measurement sensitivity threshold in the region of $10^{-11} \mu \mathrm{W} / \mathrm{cm}^{2}$.

Similar mobile technologies mean similar exposure levels There is a perception among some stakeholders that the installation of more base stations will lead to higher levels of RF in the environment. This is not the case as shown by Figure 2, which demonstrates that despite the increasing number of base stations and deployment of additional mobile technologies, the environmental levels have remained essentially constant. This would be expected as these levels are generally driven by technology needs to provide a certain signal strength to maintain service quality. It should be noted that measurements were generally taken to characterize RF exposure in the vicinity of a specific base station rather than to obtain a profile of exposures either by individuals ${ }^{58}$ or geographically. ${ }^{19}$ It is reasonable to assume that population exposure to RF exposure from mobile networks has become more ubiquitous as geographic coverage has grown and in-building coverage increased in importance.

Exposures from mobile networks are similar to broadcast services The average exposure at ground level from mobile communication technologies seen in Figure 3 is similar to that reported for broadcast services in a narrowband measurement survey of mobile communications and broadcast services in three European countries (Belgium, the Netherlands and Sweden) involving 311 locations spread over 35 areas $^{19}$ and a 200 person dosimeter survey in Eastern France. ${ }^{60}$ From an historical perspective, measurements of VHF and UHF broadcast services from 486 locations distributed throughout 15 large cities in the USA, which collectively represented $\sim 14,000$ individual measurements, reported a median exposure level of $0.005 \mu \mathrm{W} / \mathrm{cm}^{2} .66$

New surveys confirm existing exposure information

As is evidenced by Figures 1-3, exposures at ground level in public areas are a small fraction of the exposure limits and the levels vary little between countries, technologies and over time. Some countries have established fixed area RF monitoring systems, ${ }^{67}$ but we argue based on our data that such schemes provide little new information to stakeholders in comparison to targeted surveys of a sample of existing base stations. It could be further argued that post-installation surveys provide limited new information in relation to typical exposure levels. A more efficient approach to demonstrating compliance to local governments and impacted communities would be for the network operator to provide a numerical assessment before obtaining permit for the installation of the base station.

\section{CONCLUSION}

Our analysis of base station RF exposure surveys is based on over 173,000 data points from 2000 onward, across 23 countries (21 


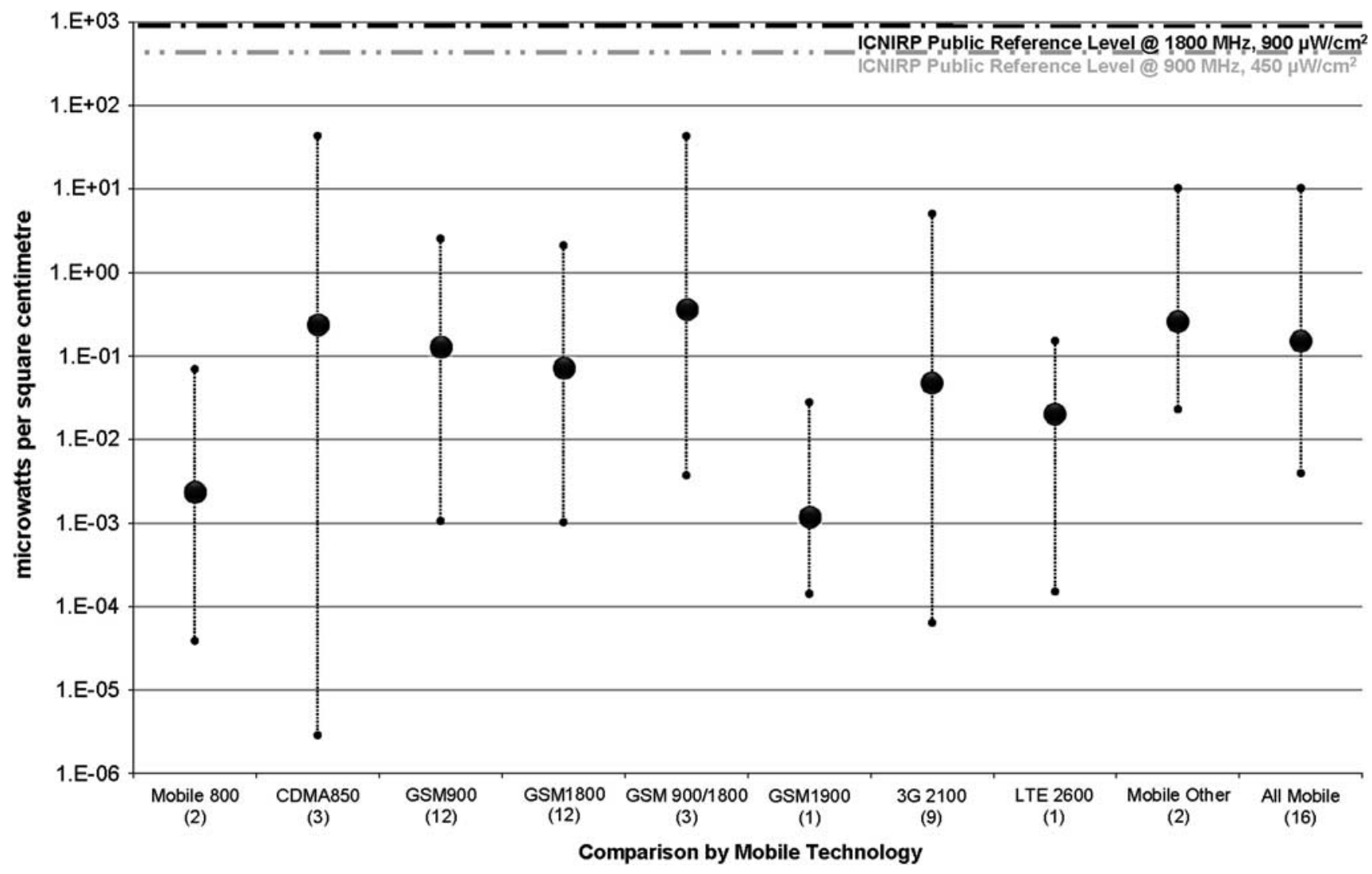

Figure 3. Minimum ( $\bullet$, maximum $(\bullet)$ and average $(\bullet)$ for each wireless technology. For comparison, ICNIRP reference levels for the public at 900 and $1800 \mathrm{MHz}$ are also plotted. Mobile Other refers to mobile technologies either not identified in the source survey or not included (e.g., PDC) in one of the other mobile technologies categories. All Mobile is the result of averaging over all mobile technologies. Only narrowband measurements (from 16 countries) could be used. The weighted averages for all available measurement years for each country were then averaged over the number of countries with measurements for each mobile technology. The figure in brackets on the horizontal axis label is the number of countries for which measurements were available for each technology.

included in the analysis) and five continents. Across all countries, years and technologies RF exposures at ground level were only a small fraction of human RF exposure standards. Importantly, there has been no significant increase in the RF exposures at ground level in public areas near base stations since the widespread introduction of $3 \mathrm{G}$ services, which had 940 million subscribers at the end of 2010, out of a total of 5.3 billion subscribers. ${ }^{1}$ Flat projections for voice traffic, the exponential growth in data and regulatory decisions allowing $2 \mathrm{G}$ spectrum to be reused for $3 \mathrm{G}$ services may see replacement of GSM with WCDMA. Figure 2 suggests that average exposure will not change and policy makers should be reassured by these results. Based on the existing data set it seems unlikely that further measurement surveys will provide substantially different exposure data. In addition, for the locations and types of installations in the original surveys postinstallation measurements at ground level for compliance purposes are unnecessary. There may be areas on rooftops and immediately in front of base station antennas where compliance levels could be exceeded and such areas need assessment. ${ }^{64}$ Although the average exposure at ground level is low, the wide variation (nine orders of magnitude) between the lowest and highest measured levels provides warning against the adoption of arbitrary RF exposure limits, which could adversely affect provision of mobile communication services.

A challenge for this type of analysis is differing measurement equipment, criteria for selection of the measurement location, settings of measurement equipment and survey methodology. Development of uniform guidance based on technical measurement standards would improve comparability of the results. Where the raw data are available, potential future analysis could include calculation of cumulative exposure distributions and investigation of the ability to combine exposure distributions with geographical and population density data to assess the distribution of exposure levels relative to population percentiles. We plan to conduct additional comparative analyses for those countries in our current data set that provide information on the RF exposures from other radio services such as broadcast television and radio. We intend to continue this work with the addition of the results of RF surveys from other countries, with data for additional years and for new mobile technologies. ${ }^{68}$ We would welcome opportunities to cooperate with other researchers.

\section{CONFLICT OF INTEREST}

Funding was provided by the GSM Association for the work of Dr. Joyner and by way of employment of Dr. Rowley.

\section{ACKNOWLEDGEMENTS}

We gratefully acknowledge the cooperation of the following individuals and organizations listed by country: Dr. Stuart Henderson and Dr. Lindsay Martin, Australian Radiation and Nuclear Protection Agency, Australia; Dr. Johannes Tomitsch, European Centre for Environmental Medicine, Austria; Josette Gallant, Industry Canada and Dr. Art Thansandote, Health Canada; Hosuk Kang, Korea Radio Promotion Agency and Professor Jeon-Ki Pack, Chungnam National University, Korea; Dr. Christian Bornkessel, IMST GmbH, Germany; Dr. H.-Peter Neitzke, ECOLOG-Institut $\mathrm{GmbH}$, Germany; Matthias Meier, Independent Consultant, Germany; Martin Gledhill, 
Ministry of Health, New Zealand; Dr. Victor Cruz Ornetta, Instituto Nacional de Investigación y Capacitación de Telecomunicaciones, Peru.; Nisakorn Manatrakul, Ministry of Public Health, Thailand; Robert D. Weller, Federal Communications Commission, USA; Richard Lee and Eileen Shields, Department of Public Health, San Francisco, USA. In addition the following industry sources assisted in identifying sources of the public information listed by organization: Dr. Sami Gabriel, Vodafone Group R\&D, UK; Dr. Joe Wiart, Orange Labs, France; Dr. Teruo Onishi, NTT DoCoMo, Japan; Peter Hidber, Forum Mobil, Switzerland; Sherif E Issa, Mobinil, Egypt; Thomas Barmüller, Mobile Manufacturers Forum. We also thank Mr. Derek Hitt for many hours of data reductions; Ms. Sandra Henderson for assistance with data entry; Professor Colin Thompson, Emeritus Professor Mathematics, University of Melbourne for assistance with the statistics and Mr. Ray McKenzie, Telstra for discussion on presentation of data. We thank the anonymous reviewers for their helpful suggestions.

\section{DISCLAIMER}

The views are solely those of the authors.

\section{REFERENCES}

1 International Telecommunications Union. ITU estimates two billion people online by end 2010, Press Release, 19 October 2010. http://www.itu.int/net/pressoffice/ press_releases/2010/39.aspx (accessed 19 December 2010) 2010.

2 World Health Organization. Base stations and wireless technologies, Fact Sheet No. 304. http://www.who.int/mediacentre/factsheets/fs304/en/index.html (accessed 19 December 2010) 2006.

$3 \mathrm{ABI}$ Research. Mobile Networks Go Green: Minimizing Power Consumption and Leveraging Renewable Energy. ABI Research: New York, 2008.

4 ICNIRP. International Commission on Non-lonizing Radiation Protection (ICNIRP) Statement on EMF-Emitting New Technologies. Health Phys 2008: 94(4): 376-392.

5 Kristiansen I.S., Elstein A.S., Gyrd-Hansen D., Kildemoes H.W., and Nielsen J.B. Radiation from mobile phone systems: is it perceived as a threat to people's health? Bioelectromagnetics 2009: 30(5): $393-401$.

6 World Health Organization. WHO research agenda for radiofrequency fields http://www.who.int/peh-emf/research/agenda/en/index.html (accessed 19 December 2010) 2010.

7 Bergqvist U., Friedrich G., Hamnerius Y., Martens L., Neubauer G., and Thuoczy G., et al. Mobile telecommunication base stations-exposure to electromagnetic fields. Report of a Short Term Mission within COST 244bis, 2001. ftp://ftp.cordis.lu/pub/ ist/docs/ka4/cost_244_base_station_emf.pdf (accessed 17 February 2012) 2001.

8 EIS-EMF (European Information System on Electromagnetic Fields Exposure and Health Impacts). Country Reports on EMF and Health: Sources, Regulations, and Risk Communication Approaches, Final Report, European Commission Joint Research Centre, February 2005. http://ec.europa.cu/health/ph_projects/2002/ pollution/fp_pollution_2002 frep_01.pdf (accessed 17 February 2012) 2005.

9 Rowley J. Wireless Networks-Regulatory Good Practice. In: Repacholi E.v.D. M.H., Ravazzani P. (Eds.). Proceedings of the International Workshop on Base Stations and Wireless Networks: Exposures and Health Consequences. World Health Oragnization, Geneva, Switzerland, pp. 145 -156, 2005.

10 ICNIRP. International Commission on Non-lonizing Radiation Protection (ICNIRP) guidelines for limiting exposure to time-varying electric, magnetic, and electromagnetic fields (up to $300 \mathrm{GHz}$ ). Health Phys 1998: 74(4): 494-522.

11 Mann S. Assessing personal exposures to environmental radiofrequency electromagnetic fields. Comptes Rendus Physique 2010: 11(9-10): 541 - 555 .

12 Troisi F., Boumis M., and Grazioso P. The Italian national electromagnetic field monitoring network. Ann Telecomm 2008: 63(1-2).

13 Henderson S., Australian Radiation and Nuclear Protection Agency (personal communication), 2010

14 Henderson S.I., and Bangay M.J. Survey of RF exposure levels from mobile telephone base stations in Australia. Bioelectromagnetics 2006: 27(1): 73 - 76

15 Line P., Cornelius W.A., Bangay M.J., and Grollo M., Levels of Radiofrequency Radiation from GSM Mobile Telephone Base Stations, ARPANSA Technical Report 129, 2000. http://www.arpansa.gov.au/pubs/eme/rfrep129.pdf (accessed 11 March 2010) 2000.

16 Tomitsch J., European Centre for Environmental Medicine (personal communication), 2010

17 Tomitsch J., Dechant E., and Frank W. Survey of electromagnetic field exposure in bedrooms of residences in lower Austria. Bioelectromagnetics 2010: 31(3): $200-208$.

18 BIPT (Belgian Institute for Postal services and Telecommunications). GSM Measurements. http://www.bipt.be/ (accessed 5 February 2003) 2003.

19 Joseph W., Verloock L., Goeminne F., Vermeeren G., and Martens L. Assessment of population exposures to RF from emerging wireless technologies in different environments. Health Phys 2012: 102(2): $161-172$.
20 Gallant J., and Thansandote A., Industry Canada and Health Canada (personal communication), 2010.

21 Health Canada. Report on: Measurement of Cellular Base-station Emissions Using a Newly Developed RF Field Mapping System. http://www.hc-sc.gc.ca/ewh-semt/ pubs/radiation/cell_base_stations/abstract-resume-eng.php (accessed 19 December 2010) 2003.

22 Nguyen B., Mohabeer S., Lai V., and Lander E., Evaluation of Electromagnetic Field Intensity in the City of Toronto. http://www.ic.gc.ca/eic/site/smt-gst.nsf/eng/ sf09392.html (accessed 11 March 2010) 2002.

23 El Messeiry M., and Issa S.E., The Cairo EMF Project (personal communication), 2010.

24 ANFR (Agence Nationale des Fréquences). Mesures de champs électromagnétiques en France: Synthèse 20071974.

25 Wiart J., Orange Labs (personal communication), 2010.

26 Neitzke H.-P., ECOLOG-Institute, Germany (personal communication), 2010.

27 Neitzke H.P., Osterhoff J., Peklo K., and Voigt H. Determination of exposure due to mobile phone base stations in an epidemiological study. Radiat Prot Dosimetry 2007: 124(1): $35-39$.

28 Bornkessel C., Institut für Mobil- und Satellitenfunktechnik (IMST GmbH), Germany (personal communication), 2010.

29 IZMF (Informationszentrum Mobilfunk). Wissenschaf(f)t Vertrauen. http://www. izmf.de/download/downloads/Broschuere_Wissenschaf_Vertrauen.pdf (accessed 11 March 2010) 2009.

30 Wuschek M., Bornkessel C., Manteuffel D., Schubert M., and Schmidt P., Möglichkeiten und Grenzen der Minimierung von Mobilfunkimmissionen: Auf Messdaten und Simulationen basierende Optionen und Beispiele, Abschlussbericht für das Bayerische Landesamt für Umweltschutz, Regensburg, 2004. http:// www.lfu.bayern.de/strahlung/fachinformationen/emf_minimierung_schirmung/ (accessed 11 March 2010) 2004.

31 Amoako J.K., Fletcher J.J., and Darko E.O. Measurement and analysis of radiofrequency radiations from some mobile phone base stations in Ghana. Radiat Prot Dosimetry 2009: 135(4): 256-260.

32 Hermes Project Greece. http://hermes.physics.auth.gr/en/desc (accessed 18 February 2012) 2010.

33 COMREG (Commission for Communications Regulation). Ireland http://www. comreg.ie/licensing and services/nir.554.444.html (accessed 11 Mar 2010) 2010.

34 Japanese MIC (Ministry of Internal Affairs and Communications). Years 2006, 2007 and 2008. http://www.tele.soumu.go.jp/j/sys/ele/body/report/index.html (accessed 11 March 2010) 2010.

35 Onishi T., NTT DoCoMo, Japan (personal communication), 2010

36 Keow M.A., and Radiman S. Assessment of radiofrequency/microwave radiation emitted by the antennas of rooftop-mounted mobile phone base stations. Radiat Prot Dosimetry 2006: 121(2): 122-127.

37 Yusof Mohd A., Rozaimah Abd R., Mohd Anuar M., and Amirul Nizam Mohd T. Microwave Radiation from Mobile Telephone Base Stations. Proceedings of the International RF and Microwave Conference, 12-14 September. IEEE, Putrajaya, Malaysia, pp. 386-389, 2006.

38 Gledhill M., Ministry of Health, New Zealand (personal communication), 2010.

39 Ministry of Health. (New Zealand). http://www.nrl.moh.govt.nz/faq/nrlvodafone monitoringproject.asp\#results (accessed 18 February 2012) 2010.

40 Cruz Ornetta V. Taller "Aspectos Técnicos Y Regulatorios Relativos A Los Efectos De Las Emisiones Electromagnéticas No lonizantes" IX Reunión Del Comité Consultivo Permanente II. Comision Interamericana De Telecomunicaciones (Citel): San Salvador, El Salvador, 2007.

41 Korea Radio Promotion Agency. http://korpa.or.kr/online/sub02/sub02_91.jsp (accessed 18 February 2012) 2010.

42 Suk K.H., Korea Radio Promotion Agency (personal communication), 2010.

43 MITC (Ministerio de Industria, Energía y Turismo). http://www.minetur.gob.es/ telecomunicaciones/Espectro/NivelesExposicion/Paginas/Informes.aspx (accessed 18 February 2012) 2010.

44 Anger G., and Trulsson J., Spectral measurements of radio frequency electromagnetic fields between $60 \mathrm{MHz}$ and $3.4 \mathrm{GHz}$. The years 2001 to 2007 in Sweden SSI Rapport: 2008-13, Swedish Radiation Protection Authority. http://www.stralsakerhetsmyndigheten.se/Global/Publikationer/Rapport/Stralskydd/2008/ssi-rapp2008-13.pdf (accessed 11 March 2010) 2008

45 Forum Mobil. (Switzerland). http://forummobil.org/userdocs/documents/PM\%20 Streetparade.pdf (accessed 18 February 2012) 2004.

46 Forum Mobil. (Switzerland). http://www.forummobil.ch/de/das-forum/medienmit teilungen/geringe-strahlenbelastung-durch-mobilfunk-1267432768 (accessed 11 March 2010) 2006

47 Government Council of the Canton of Zürich. Joint Press Release Zurich Department of Waste, Water, Energy \& Air and Forum Mobile: "Mobile-limits respectedsensitive places and major events", 08/235-03, Communications Department of the Government Council of the Canton of Zürich, Switzerland, 2008.

48 Hidber P., Forum Mobil, Switzerland (personal communication), 2010. 
49 Kanton Zurich. Immissionsmessungen NIS-Strahlenbelastung durch Mobilfunk und andere Quellen (2009-2010). http://www.awel.zh.ch/internet/baudirektion/ awel/de/luft_asbest_elektrosmog/elektrosmog/messungen.html, 2011 (accessed 18 February 2012)

50 Woweries K. Bericht Langzeit-Immissionsmessungen im Kanton Zürich, doc 2/24. Inventis AG, Zürich, 1974a.

51 Woweries K. Bericht Langzeit-Immissionsmessung Streetparade, doc 1/22. Inventis AG, Zürich, 1974b.

52 Hanprated N., Electromagnetic Radiation Intensity Profile from Mobile Phone Base Stations and Subjective Symptoms among Office Workers. MSc thesis, Mahidol University, Thailand, 2007.

53 Manatrakul N., Thansandote A., Gajida G., Lemay E., Chancunapas P., and JP M. Measurements of ground-level emissions from mobile Phone base stations in Bangkok using a low-cost RF field measurement system. Asian J Radiol 2005: XI(III): $181-188$

54 Manatrakul N., Ministry of Public Health, Thailand (personal communication), 2010.

55 OFCOM. United Kingdom Office of Communications: Mobile phone base station audits. http://www.ofcom.org.uk/sitefinder/audits/ (accessed 18 February 2012) 2010.

56 Lee R., and Shields E., Department of Public Health San Francisco, USA (personal communication), 2010

57 Trinchero D. Exposure assessment procedures in presence of wideband digital wireless networks. Radiat Prot Dosimetry 2009: 137(3-4): 236-242.

58 Joseph W., Frei P., Roösli M., Thuróczy G., Gajsek P., and Trcek T., et al. Comparison of personal radio frequency electromagnetic field exposure in different urban areas across Europe. Environ Res 2010: 110(7): 658-663.

59 Blas J., Lago F.A., Fernández P., Lorenzo R.M., and Abril E.J. Potential exposure assessment errors associated with body-worn RF dosimeters. Bioelectromagnetics 2007: 28(7): $573-576$.
60 Viel J.-F., Clerc S., Barrera C., Rymzhanova R., Moissonnier M., and Hours M., et al. Residential exposure to radiofrequency fields from mobile-phone base stations, and broadcast transmitters: a population-based survey with personal meter. Occup Environ Med 2009: 66(8): 550-556.

61 Narda Safety Test Solutions GmbH. E-Field Probe: EF0391-Measuring electric fields from $100 \mathrm{kHz}$ to $3 \mathrm{GHz}$ using instruments in the NBM-500 family. http://www. narda-sts.de/pdf/hochfrequenz/DS_EF0391_EN.pdf (accessed 18 February 2012) 2009.

62 Bornkessel C., Schubert M., Wuschek M., and Schmidt P. Determination of the general public exposure around GSM and UMTS base stations. Radiat Prot Dosimetry 2007: 124(1): 40-47.

63 Wireless Intelligence. Market Data. https://www.wirelessintelligence.com/ (accessed 18 February 2012) 2011.

64 Alanko T., Hietanen M., and Nandelstadh P. Occupational exposure to RF fields from base station antennas on rooftops. Ann Telecomm 2008: 63(1 - 2): 125-132.

65 FCC.. Federal Communications Commission (FCC) guidelines for evaluating the environmental effects of radiofrequency radiation, ET Docket 93-62. Federal Register 1996: 61(153): 41006-41019.

66 Tell R.A., and Mantiply E.D. Population exposure to VHF and UHF broadcast radiation in the united states. Proc IEEE 1980: 68(1): 6-12.

67 Oliveira C., Sebastijo D., Carpinteiro G., Correia L.M., Fernandes C.A., and Serralha A et al. The moniT Project: Electromagnetic Radiation Exposure Assessment in Mobile Communications. IEEE Antennas and Propagation Magazine 2007: 49(1): 44-53.

68 Coray R., Krähenbühl P., Riederer M., Stoll D., Neubauer G., and Szentkuti B. NIR Exposure of Salzburg. Federal Communications Commission (ComCom), 1974.

(c) This work is licensed under the Creative Commons AttributionSOMERIEHISRESERVED NonCommercial-No Derivative Works 3.0 Unported License. To view a copy of this license, visit http://creativecommons.org/licenses/by-nc-nd/3.0/ 